\title{
MENA 1.1- An Updated Geophysical Regionalization of the Middle East and North Africa
}

W.R. Walter, M.E. Pasyanos, J. Bhattacharyya and J. O'Boyle

\section{March 1, 2000}

U.S. Department of Energy

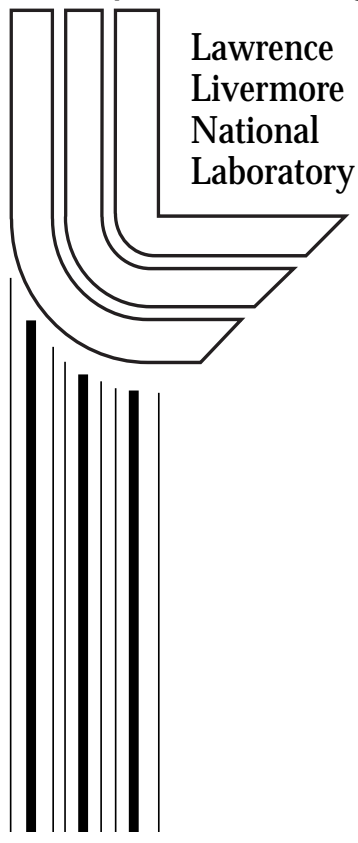




\section{DISCLAIMER}

This document was prepared as an account of work sponsored by an agency of the United States Government. Neither the United States Government nor the University of California nor any of their employees, makes any warranty, express or implied, or assumes any legal liability or responsibility for the accuracy, completeness, or usefulness of any information, apparatus, product, or process disclosed, or represents that its use would not infringe privately owned rights. Reference herein to any specific commercial product, process, or service by trade name, trademark, manufacturer, or otherwise, does not necessarily constitute or imply its endorsement, recommendation, or favoring by the United States Government or the University of California. The views and opinions of authors expressed herein do not necessarily state or reflect those of the United States Government or the University of California, and shall not be used for advertising or product endorsement purposes.

Work performed under the auspices of the U. S. Department of Energy by the University of California Lawrence Livermore National Laboratory under Contract W-7405-Eng-48.

This report has been reproduced directly from the best available copy.

Available to DOE and DOE contractors from the

Office of Scientific and Technical Information

P.O. Box 62, Oak Ridge, TN 37831

Prices available from (423) 576-8401

http://apollo.osti.gov/bridge/

Available to the public from the National Technical Information Service

U.S. Department of Commerce 5285 Port Royal Rd., Springfield, VA 22161 http://www.ntis.gov/

OR

Lawrence Livermore National Laboratory Technical Information Department's Digital Library http://www.llnl.gov/tid/Library.html 


\title{
MENA 1.1 - An Updated Geophysical Regionalization of the Middle East and North Africa
}

\author{
W. R. Walter \\ M. E. Pasyanos \\ J. Bhattacharyya \\ Jennifer O’Boyle \\ Geophysics and Global Security Division \\ Earth and Environmental Sciences Directorate \\ Lawrence Livermore National Laboratory
}

\section{Introduction}

This short report provides an update to the earlier LLNL paper entitled "Preliminary Definition of Geophysical Regions for the Middle East and North Africa" (Sweeney and Walter, 1998). This report is designed to be used in combination with that earlier paper. The reader is referred to Sweeney and Walter (1998) for all details, including definitions, references, uses, shortcomings, etc., of the regionalization process. In this report we will discuss only those regions in which we have changed the boundaries or velocity structure from that given by the original paper.

The paper by Sweeney and Walter (1998) drew on a variety of sources to estimate a preliminary, first-order regionalization of the Middle East and North Africa (MENA), providing regional boundaries and velocity models within each region (see Figure 1). The model attempts to properly account for major structural discontinuities and significant crustal thickness and velocity variations on a gross scale. The model can be used to extrapolate sparse calibration data within a distinct geophysical region. This model can also serve as a background model in the process of forming station calibration maps using intelligent interpolation techniques such as kriging, extending the calibration into aseismic areas. Such station maps can greatly improve the ability to locate and identify seismic events, which in turn improves the ability to seismically monitor for underground nuclear testing.

The original model from Sweeney and Walter (1998) was digitized to a $1^{\circ}$ resolution, for simplicity we will hereafter refer to this model as MENA 1.0. The new model described here has also been digitized to a $1^{\circ}$ resolution and will be referred to as MENA1.1 throughout this report.

\section{Reasons for Model Changes}

As discussed in the original paper, the regionalization process is meant to be iterative, with each successive model improving on the earlier one. There were 
several changes planned for the MENA1.1 update to the MENA1.0 model, including changes required to match with a new Western Eurasia (WEA) model being developed. In summary the five main reasons for this update are to:

1) Fixing a few small errors in MENA1.0

2) Improving MENA1.0 periphery regions (regions 1 and 17-28)

3) Provide seamless transition to a new WEA model (Bhattacharyya et al., 2000).

4) Subdividing regions that stand out in surface wave tomography studies.

5) Improve the geo-coding or registration of the boundaries

The first changes to MENA1.0 are to fix some small errors. For example in region 9, the Pn in the velocity table in the appendix was incorrectly typed in. The next major changes were to improve the regions outside of the continental part of the Middle East and North Africa proper. Because the focus of the original MENA1.0 paper was on the continental parts of the Middle East and North Africa, less analysis was done on defining the regions outside of this zone. As discussed in Sweeney and Walter (1998) the broad ocean region 1 was mostly pro-forma and the analysis of regions outside the Middle East and North Africa were abbreviated. In MENA1.1 we wanted to better define the boundaries and models for these regions.

Part of the motivation for improving these regions came from the need to match the Western Eurasia (WEA) geophysical regionalization being done by

Bhattacharyya et al. (2000). In particular we wanted the boundaries and velocity models of the two regionalizations to match exactly so that there would be a seamless transition between the two. To ensure this we revised the boundaries of the northern tier of regions $(20,21,23,26,27$ and 28) in MENA1.0 to both improve their definition and to match boundaries in WEA. We slightly modified the velocity model of region 28 to be consistent with Bhattacharyya et al. (2000), and supplied the velocity models of the other northern tier regions to Joydeep Bhattacharyya for inclusion in the WEA regionalization. Finally we added the southern most portion of the Urals as a new region 29. The revised boundaries are shown in Figure 2.

The next major changes were influenced by regional and global surface wave tomography results (e.g. Pasyanos et al., 2000; Ritsema and van Heijst, 2000). In particular the ocean rift systems show up prominently in these studies as slow regions and we have decided to separate rift regions out as region $1 \mathrm{~A}$. It is important to note here that we did NOT use the tomography studies to choose the boundaries of the regions, these were chosen based on bathymetry and seismicity. The other major feature apparent in the surface wave tomography studies is the fast velocity at longer periods ( $>50$ s) associated with the Archean cratons in Western and Central Africa. Again we used geophysical boundaries to subdivide the original region 5 and create two new regions $5 \mathrm{~A}$.

The final major change is in the geo-coding or registration of the boundaries. The original MENA1.0 model (see figure 1) was done using control points from the Exxon maps (Kaplan et al., 1985) as well as using topography and bathymetry. For MENA1.1 we started by modifying this conceptual figure to 
update the boundaries as described in detail for each region below. This gives the initial boundaries for MENA1.1 as shown in Figure 2. These boundaries were then put into a GIS system and laid over a digitized version of the Exxon map (Kaplan et al.,1985). We then adjusted the boundaries to improve the match which is shown in Figure 3. This step is particularly important for regions that are partly defined by the sediment contours such as regions 6, 7, 8, 20 and 22. This greatly improved the overall geo-registration of the entire model. Finally the polygons for each region were gridded on a $1^{\circ}$ basis and a block model produced as shown in Figure 4. This model is then ready for use in modeling codes. Because the model is now in GIS format it is straightforward to redigitize it at coarser or finer block sizes. This will be important in future work, both to test the model against others that have different block sizes and to move to finer grids to improve the resolution of future models.

\section{Modifications by Region}

Region 1 - Oceanic crust of the Atlantic and Indian Oceans Region $1 \mathrm{~A}$ - Ocean ridges

In MENA 1.0 we were primarily concerned with continental structure and so the description of this region was simplified: we used the CRUST 5.1 (Mooney et al., 1998) model A0 for the whole ocean. Not unexpectedly, regional surface-wave tomography (e.g. Pasyanos et al., 2000; Ritsema and van Heijst, 2000) shows the active ridges in the Indian ocean as slow. We used bathymetry and seismicity as criteria to separate the oceanic ridges as model $1 \mathrm{~A}$. We modified model A0 by thinning the water layer from $5 \mathrm{~km}$ to $3 \mathrm{~km}$ and thinning the lower crust by 0.5 $\mathrm{km}$. Finally we decreased the Pn velocity to $7.9 \mathrm{~km} / \mathrm{s}$. We changed the remaining ocean from CRUST 5.1 model A0 ( $0.15 \mathrm{~km}$ sediment) to A2 (1 km of sediment) as more representative of the average sediment layer in the remainder of the ocean. In future work we would like to investigate further subdividing the ocean crust by age.

\section{Region 4 - Red Sea Continental Rift Zone}

In MENA1.0 the region had a crustal thickness of 23.5. Global models such as 3SMAC (Nataf and Ricard, 1996) show a thinning from north to central Red Sea with an average thickness probably closer to $18 \mathrm{~km}$. This is consistent with local refraction data as discussed in Sweeney and Walter (1998). We thinned the upper, middle and lower crustal layers by $2 \mathrm{~km}$ each to make an $18 \mathrm{~km}$ thick model.

Region 5 - African platform

Region 5A - African Archean cratons

This was the largest undivided continental region in the original MENA1.0 model. Because so little seismic data was available there were a number of 
uncertainties on how best to subdivide it. With the recent regional surface-wave group-velocity (Pasyanos et al., 1999) and phase-velocity (Ritsema and Heijst, 2000) results, it is clear the Archean cratons, in west Africa and the Congo, have much faster upper mantle structures than their surroundings. We have separated them out as region $5 \mathrm{~A}$ and their structure is consistent with an interpretation of an old, thick and fast upper mantle lid. Because this is a geophysical regionalization we have not tried to explicitly match the surface wave velocities. Rather we have used an Archean model GA from CRUST 5.1 (Mooney et al., 1998). The West African Cratonic boundary was determined using boundaries given in Hazler (1998) based on Cahen and Snelling (1984). The northern boundary of the Central African region 5A includes some of the Central African Mobile Belt (e.g. Hazler, 1998) as well as the Congo craton. We used the outcrop of Archean granites to define this boundary for the most part though we stayed south of the volcanic Cameroon Line. The remaining part of region 5 was left the same as in MENA1.0 except that we have slightly decreased the Pn velocity from $8.2 \mathrm{~km} / \mathrm{s}$ to $8.1 \mathrm{~km} / \mathrm{s}$.

Region 6 - Arabian platform, thin sediments

Region 7 - Eastern Arabian platform, sediments thicker than $2 \mathrm{~km}$

Region 8 - North Africa marginal basins

We have slightly adjusted the boundaries to better match the Exxon map (Kaplan et al., 1985) sediment contours. For region 6 we have changed the northern boundary from the geologic outcrop-sediment boundary to the East Anatolian fault.

Region 9 - Atlas - Betic orogenic zone

We have decreased Pn velocity from $8.2 \mathrm{~km} / \mathrm{s}$ to $8.0 \mathrm{~km} / \mathrm{s}$. This was an error in MENA1.0 model table since as noted in the description of previous studies in the area the Pn velocities range from 7.8 to $8.1 \mathrm{~km} / \mathrm{s}$ (Sweeney and Walter, 1998).

Region 18 - Afar triangle

All evidence points to very slow velocities in the upper mantle decreasing for this triple junction plume (e.g. Knox et al., 1998). We have slightly decreased the Pn velocity from $7.8 \mathrm{~km} / \mathrm{s}$ to $7.7 \mathrm{~km} / \mathrm{s}$.

Region 20 - Caspian depression

The boundaries were slightly modified and made consistent with WEA region 7 in Bhattacharyya et al. (2000). 
Region 21 - Kazakhstan platform

This region is consistent with WEA region 9 in Bhattacharyya et al. (2000).

Region 22 - Caucasus and Kopet Dag forelands

The original eastern boundary for this region was artificial. We have adjusted the boundaries to encompass all of the sediment basins in the Caucus and Kopet Dag forelands as indicated in the Exxon map (Kaplan et al., 1985).

Region 23 - Russian platform

This region is consistent with WEA region 6 in Bhattacharyya et al. (2000).

Region 25 - Afghanistan-Hindu Kush orogenic zone

There are several models in CRUST5.1 that cover this region. We originally used a platform based model D9, but in retrospect this does not seem like the right kind of tectonic model for this orogenic region. The crust was too thin $(41 \mathrm{~km})$ and the average velocity appear too fast when compared to the surface wave models (e.g. Pasyanos et al., 2000). A better CRUST5.1 model that Mooney et al. (1998) also uses in this region is the orogen based model P4. This model has a thicker $(50 \mathrm{~km})$ and slower crust. We now use it here.

Region 26 - Pannonian basin

We have used the Exxon map (Kaplan et al., 1985) map to slightly adjust the boundaries to encompass all of Pannonian Basin area.

Region 27 - Alps -Dinarides orogenic zone

Region 27A - Italy-Adriatic-Corsica-Sardina thinned crust

The original region 27 had very significant crustal thickness differences within it, ranging from more than $50 \mathrm{~km}$ in the Alps to less than $30 \mathrm{~km}$ in the Adriatic (e.g. Du et al., 1998). To make more consistent regions we have split the original into two regions: Alps and Dinarides, which are collisional zones with thicker crust $(40-50 \mathrm{~km})$, are region 27. Italy and Adriatic Sea are region 27A with average crustal thickness of 25-35. We have added Corsica and Sardinia to region 27A.

In the original region 27 we used the CRUST5.1 1 Alps and Forelands orogen model P2 . For the new region 27 we have modified this model to have thicker crust ( from $38 \mathrm{~km}$ to $42 \mathrm{~km}$ ) to better match the average crustal thickness of the region (Du et al., 1998). For the new region 27A we have grouped Corsica and Sardinia with Italy and the Adriatic despite their different original continental 
affiliations (European rather than African) because of similar apparent crustal thicknessess and structures. For this region we used the CRUST5.1 extended crust model N2 similar to what we are using in Western Europe.

Region 28 - Western Europe extended crust

We have adjusted the boundaries slightly to reflect changes to regions 26 and 27. We also changed the base model from CRUST 5.1 model N3 to N2 (slightly less sediment) and slightly thickened the crust from 31 to $33 \mathrm{~km}$ to make it consistent with Bhattacharyya et al. (2000), WEA region 5.

Region 29 - Ural mountains

This is a new region to encompass the southern most extension of the Urals. We have used a modification of CRUST5.1 model P1 here as discussed by Bhattacharyya et al., 2000, for WEA region 8.

\section{Future Work}

As discussed in Sweeney and Walter (1998) the a priori modeling process is meant to be iterative. This is first in a series of steps to improve the MENA model. Work is now in progress to compare the predictions of this a priori model to observations using travel times, surfaces wave group velocities, regional waveform modeling, receiver functions and other data. The next iteration should draw on the results of these validation tests.

We are also currently testing two potential improvements to this model. First we are replacing the gross scale average sediment models given here with more detailed sediment velocity models (e.g. Laske and Masters, 1997). Second we are extending the model deeper by incorporating other upper mantle regionalizations such as RUM (Gudmundsson and Sambridge, 1998) at fixed depths below MENA1.1. We will report on these extended models and validation tests on them in a future paper.

Acknowledgements. We thank Jerry Sweeney, Megan Flanagan, and Steve Myers for comments that improved the model. This work was performed under the auspices of the U.S. Department of Energy by the University of California, Lawrence Livermore National Laboratory, under contract W-7405-ENG-48.

\section{References}

Bhattacharyya, J., W. R. Walter, M. Flanagan, M. E. Pasyanos, and J. O'Boyle, 2000, Preliminary definition of geophysical regions in Western Eurasia, UCRLID-??????. 
Cahen and Snelling, 1984, The geochronology and evolution of Africa, Oxford, Clarendon Press.

Du, Z. J., A. Michelini and G. F. Panza, 1998, EurID: a regionalized 3-D seismological model of Europe, Phys. Earth Planet. Inter., 105, 31-62.

Gudmundsson, O and M. Sambridge, 1998, A regionalized upper mantle (RUM) seismic model, J. Geophys. Res., 103, 7121-7136.

Hazler, S. E., 1998, One-dimensional velocity structure of northern Africa as determined by Rayleigh wave group velocity dispersion, Masters Thesis, University of Colorado, Boulder, 120 pp.

Kaplan, A., C. U. Lusser, and I. O. Norton, 1985, Tectonic Map of the World, Panels 9,10,11 (1:10,000,000 Mercator): Exxon Research Company.

Knox, R. P., A. A. Nyblade and C. A. Langston, 1998, Upper mantle S velocities beneath Afar and western Saudi Arabia from Rayleigh wave dispersion, Geophysical Research Letters, 25, 4233-4236.

Laske, G. and T. G. Masters, 1997, A global digital map of sediment thickness, EOS Trans., suppl. 78, F483.

Mooney, W. D., G. Laske, and T. G. Masters, 1998, CRUST 5.1: A global crustal model at $5^{\circ} \times 5^{\circ}$ : Journal of Geophysical Research, 103, p. 727-747.

Nataf, H. -C., and Y. Ricard, 1996, 3SMAC: an apriori tomographic model of the upper mantle based on geophysical modeling, Phys. Earth Planet. Inter., 95, 101122.

Pasyanos, M. E., W. R. Walter and S. E. Hazler, 2000, A surface wave dispersion study of the Middle East and North Africa for Monitoring the Comprehensive Nuclear-Test-Ban Treaty , Pure and Appl. Geophys. (in press).

Ritsema, J. and H. van Heijst, 2000, New seismic model of the upper mantle beneath Africa, Geology, 28, 63-66.

Sweeney, J., and W. R. Walter, 1998, Preliminary definition of geophysical regions for the Middle East and North Africa, UCRL-ID-132899 Lawrence Livermore National Laboratory Report, 38 pp. 


\section{Figure Captions}

Figure 1. Map of the conceptual MENA1.0 model from Sweeney and Walter (1998). The geophysical regionalization boundaries shown in color and numbered. The region boundaries are drawn on top of a background of topography and bathemetry, earthquakes from the NEIC bulletin (yellow circles are depth less than $50 \mathrm{~km}$, orange circles are depth $50-200 \mathrm{~km}$, red circles are depths $>200 \mathrm{~km}$, and blue are unknown depth designated $33 \mathrm{~km}$ by NEIC), primary and secondary IMS seismic stations (stars and diamonds). A one-degree grid is superimposed indicating the resolution of the computer reference models.

Figure 2. Map of the conceptual MENA1.1 model in the same format as Fig. 1. Note that a number of small boundary shifts have occurred compared to Fig. 1 as described in the text. Where MENA1.0 regions have been subdivided the subregions have dotted boundaries and are labeled with the suffix " $\mathrm{A}$ ".

Figure 3. Map showing the MENA1.1 regions on top of some of the Exxon (Kaplan et al. 1985) maps for the region. These boundaries have now been adjusted from the conceptual boundaries in Fig. 2 for geo-coding and to better track geologic features. See text for details. Also shown is the southern edge of the WEA model (Bhattacharyya et al., 2000) to demonstrate that the boundaries match exactly between the two models.

Figure 4. Map showing the geo-coded 1-degree digitized computer model MENA1.1 


\section{Appendix - Revised Velocity Models}

Velocity models for geophysical regions. Depths are in kilometers, velocities are in km/s. Model format follows the CRUST5.1 model of Mooney et al. (1998); mantle Vs values are adjusted to be consistent with a Vp/Vs ratio of 1.77. An asterisk designates a modification from the original CRUST5.1 model. A "\#" indicates a change from the original MENA1.0 model by Sweeney and Walter (1999). Completely new regions are designated by the original region number followed by an "A". See text for details.

\begin{tabular}{|c|c|c|c|}
\hline Region 1 & \multicolumn{3}{|c|}{ Model CRUST5.1 A2\# } \\
\hline Depth & $\mathrm{Vp}$ & Vs & density \\
\hline 0.00 & 1.50 & 0.00 & 1.02 \\
\hline 5.00 & 2.10 & 0.90 & 2.10 \\
\hline 6.00 & 5.00 & 2.50 & 2.60 \\
\hline 7.70 & 6.60 & 3.65 & 2.90 \\
\hline 10.00 & 7.10 & 3.90 & 3.05 \\
\hline 12.50 & 8.15 & 4.61 & 3.40 \\
\hline
\end{tabular}

Region 1A Model CRUST5.1 A0*

\begin{tabular}{|c|c|c|c|}
\hline Depth & $\underline{\mathrm{Vp}}$ & $\underline{\mathrm{VS}}$ & density \\
\hline 0.00 & 1.50 & 0.00 & 1.02 \\
\hline 3.00 & 1.80 & 0.70 & 1.70 \\
\hline 3.15 & 5.00 & 2.50 & 2.60 \\
\hline 4.85 & 6.60 & 3.65 & 2.90 \\
\hline 7.15 & 7.10 & 3.90 & 3.05 \\
\hline 9.15 & 7.90 & 4.46 & 3.40 \\
\hline
\end{tabular}

Region 2 Model CRUST5.1 B4*

\begin{tabular}{|c|c|c|c|}
\hline Depth & $\underline{\mathrm{Vp}}$ & $\underline{\mathrm{VS}}$ & density \\
\hline 0.00 & 1.50 & 0.00 & 1.02 \\
\hline 5.00 & 2.30 & 1.10 & 2.20 \\
\hline 8.50 & 3.20 & 1.60 & 2.30 \\
\hline 11.20 & 5.00 & 2.50 & 2.60 \\
\hline 14.50 & 6.60 & 3.65 & 2.90 \\
\hline 19.00 & 7.10 & 3.90 & 3.05 \\
\hline 24.00 & 8.00 & 4.52 & 3.35 \\
\hline
\end{tabular}

Region 3 Model CRUST5.1 Y2

\begin{tabular}{|c|c|c|c|}
\hline Depth & $\underline{V p}$ & $\underline{\mathrm{VS}}$ & density \\
\hline 0.00 & 2.20 & 1.10 & 2.20 \\
\hline 1.00 & 4.00 & 2.00 & 2.40 \\
\hline 8.00 & 6.00 & 3.40 & 2.70 \\
\hline 13.00 & 6.60 & 3.70 & 2.90 \\
\hline 19.00 & 7.20 & 4.00 & 3.05 \\
\hline 26.00 & 8.00 & 4.52 & 3.35 \\
\hline
\end{tabular}




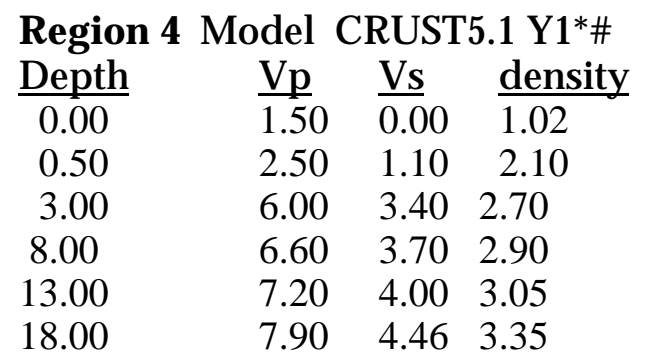

Region 5 Model CRUST5.1 I7*\&

$\begin{array}{ccccc}\frac{\text { Depth }}{0.00} & & \frac{\mathrm{Vp}}{2.50} & \frac{\mathrm{Vs}}{1.10} & \frac{\text { density }}{2.10} \\ 0.50 & & 4.00 & 2.10 & 2.40 \\ 1.00 & & 6.20 & 3.60 & 2.80 \\ 14.00 & 6.60 & 3.70 & 2.90 \\ 27.00 & 7.30 & 4.00 & 3.10 \\ 40.00 & & 8.10 & 4.58 & 3.40\end{array}$

Region 5A Model CRUST5.1 GA*

\begin{tabular}{|c|c|c|c|}
\hline Depth & $\underline{\mathrm{Vp}}$ & $\underline{\mathrm{Vs}}$ & density \\
\hline 0.00 & 2.50 & 1.10 & 2.10 \\
\hline 0.25 & 4.00 & 2.10 & 2.40 \\
\hline 0.50 & 6.20 & 3.60 & 2.80 \\
\hline 13.00 & 6.40 & 3.65 & 2.85 \\
\hline 26.00 & 6.80 & 3.80 & 2.95 \\
\hline 39.00 & 8.20 & 4.63 & 3.40 \\
\hline
\end{tabular}

Region 6 Model CRUST5.1 I2*

\begin{tabular}{|c|c|c|c|}
\hline Depth & $\underline{\mathrm{Vp}}$ & $\underline{\mathrm{VS}}$ & density \\
\hline 0.00 & $\overline{2.50}$ & $\overline{1.10}$ & 2.10 \\
\hline 0.10 & 4.00 & 2.10 & 2.40 \\
\hline 1.00 & 6.20 & 3.60 & 2.80 \\
\hline 14.00 & 6.60 & 3.70 & 2.90 \\
\hline 28.00 & 7.30 & 4.00 & 3.10 \\
\hline 40.00 & 7.90 & 4.46 & 3.35 \\
\hline
\end{tabular}

Region 7 Model CRUST5.1 D2*

\begin{tabular}{rllll} 
Depth & & $\frac{\text { Vp }}{\text { Vs }}$ & & density \\
\hline 0.00 & & 2.50 & 1.10 & 2.10 \\
2.00 & & 4.50 & 2.40 & 2.50 \\
11.00 & & 6.20 & 3.60 & 2.80 \\
21.00 & & 6.60 & 3.70 & 2.90 \\
34.00 & & 7.30 & 4.00 & 3.10 \\
42.00 & & 8.10 & 4.58 & 3.40
\end{tabular}


Region 8 Model CRUST5.1 T5*

\begin{tabular}{rllll} 
Depth & & $\frac{\mathrm{Vp}}{\mathrm{V}}$ & $\frac{\mathrm{Vs}}{\mathrm{Na}}$ & density \\
\hline 0.00 & & 2.50 & 1.10 & 2.10 \\
1.00 & & 4.00 & 2.10 & 2.40 \\
5.00 & & 6.00 & 3.40 & 2.70 \\
14.00 & & 6.60 & 3.70 & 2.90 \\
24.00 & & 7.20 & 4.00 & 3.10 \\
34.00 & & 8.00 & 4.52 & 3.35
\end{tabular}

Region 9 Model CRUST5.1 T6*

\begin{tabular}{|c|c|c|c|}
\hline Depth & $V p$ & Vs & density \\
\hline 0.00 & $\overline{2.50}$ & $\overline{1.10}$ & 2.10 \\
\hline 0.50 & 4.00 & 2.10 & 2.40 \\
\hline 1.00 & 6.00 & 3.40 & 2.70 \\
\hline 12.00 & 6.60 & 3.70 & 2.90 \\
\hline 24.00 & 7.20 & 4.00 & 3.10 \\
\hline 34.00 & 8.00 & 4.52 & 3.40 \\
\hline
\end{tabular}

Region 10, 13, 14, 15 Model CRUST5.1 P1

\begin{tabular}{|c|c|c|c|}
\hline Depth & $\underline{V p}$ & $\underline{\mathrm{Vs}}$ & density \\
\hline 0.00 & 2.50 & $\overline{1.10}$ & 2.10 \\
\hline 1.00 & 4.00 & 2.10 & 2.40 \\
\hline 2.00 & 6.10 & 3.50 & 2.75 \\
\hline 22.00 & 6.30 & 3.60 & 2.80 \\
\hline 42.00 & 7.20 & 4.00 & 3.10 \\
\hline 46.00 & 7.90 & 4.46 & 3.35 \\
\hline
\end{tabular}

Region 11 Model CRUST5.1 Q0*

\begin{tabular}{|c|c|c|c|}
\hline Depth & $\underline{V p}$ & $\underline{\mathrm{Vs}}$ & density \\
\hline 0.00 & 2.50 & 1.10 & 2.10 \\
\hline 1.00 & 5.30 & 3.10 & 2.60 \\
\hline 4.00 & 6.10 & 3.50 & 2.75 \\
\hline 26.00 & 6.60 & 3.80 & 2.90 \\
\hline 42.00 & 7.20 & 4.00 & 3.10 \\
\hline 46.00 & 7.90 & 4.46 & 3.35 \\
\hline
\end{tabular}

Region 12 Model CRUST5.1 R0*

\begin{tabular}{|c|c|c|c|}
\hline Depth & $\underline{V p}$ & $\underline{V s}$ & density \\
\hline 0.00 & 2.50 & $\overline{1.10}$ & 2.10 \\
\hline 1.00 & 4.00 & 2.10 & 2.40 \\
\hline 9.00 & 6.00 & 3.50 & 2.70 \\
\hline 19.00 & 6.40 & 3.70 & 2.85 \\
\hline 39.00 & 7.10 & 3.90 & 3.05 \\
\hline 50.00 & 8.00 & 4.52 & 3.35 \\
\hline
\end{tabular}

Region 13, 14, and 15 (see model for Region 10) 
Region 16 Model CRUST5.1 L1*

\begin{tabular}{|c|c|c|c|}
\hline Depth & $\underline{\mathrm{Vp}}$ & $\underline{\mathrm{Vs}}$ & density \\
\hline 0.00 & $\overline{2.50}$ & $\overline{1.10}$ & 2.10 \\
\hline 1.00 & 4.00 & 2.10 & 2.40 \\
\hline 4.00 & 6.00 & 3.50 & 2.70 \\
\hline 12.00 & 6.60 & 3.70 & 2.90 \\
\hline 29.00 & 7.20 & 4.00 & 3.10 \\
\hline 40.00 & 8.00 & 4.52 & 3.35 \\
\hline
\end{tabular}

Region 17 Model CRUST5.1 T7*

$\begin{array}{cllll}\text { Depth } & & \frac{\mathrm{Vp}}{\mathrm{V}} & \frac{\mathrm{Vs}}{\mathrm{d}} & \text { density } \\ 0.00 & & 2.50 & 1.10 & 2.10 \\ 1.00 & & 4.00 & 2.10 & 2.40 \\ 3.50 & & 6.00 & 3.40 & 2.70 \\ 13.50 & & 6.60 & 3.70 & 2.90 \\ 24.00 & & 7.20 & 4.00 & 3.10 \\ 34.00 & & 7.90 & 4.46 & 3.35\end{array}$

Region 18 Model CRUST5.1 A0*\#

\begin{tabular}{|c|c|c|c|}
\hline Depth & $\underline{V p}$ & $\underline{\mathrm{Vs}}$ & density \\
\hline 0.00 & $\overline{1.80}$ & $\overline{0.70}$ & $\overline{1.70}$ \\
\hline 0.15 & 5.00 & 2.50 & 2.60 \\
\hline 1.85 & 6.60 & 3.65 & 2.90 \\
\hline 4.15 & 7.10 & 3.90 & 3.05 \\
\hline 6.65 & 7.70 & 4.35 & 3.35 \\
\hline
\end{tabular}

Region 19 Model CRUST5.1 I2*

\begin{tabular}{|c|c|c|c|}
\hline Depth & $\underline{V p}$ & $\underline{\mathrm{Vs}}$ & density \\
\hline 0.00 & 2.50 & 1.10 & 2.10 \\
\hline 0.10 & 4.00 & 2.10 & 2.40 \\
\hline 0.90 & 6.20 & 3.60 & 2.80 \\
\hline 11.00 & 6.60 & 3.70 & 2.90 \\
\hline 21.00 & 7.30 & 4.00 & 3.10 \\
\hline 33.00 & 7.90 & 4.46 & 3.35 \\
\hline
\end{tabular}

Region 20 Model CRUST5.1 Y7

\begin{tabular}{|c|c|c|c|}
\hline Depth & $\mathrm{Vp}$ & Vs & density \\
\hline 0.00 & 2.50 & $\overline{1.10}$ & 2.10 \\
\hline 1.00 & 4.00 & 2.10 & 2.40 \\
\hline 12.00 & 6.00 & 3.40 & 2.70 \\
\hline 17.00 & 6.60 & 3.70 & 2.90 \\
\hline 29.00 & 7.10 & 3.90 & 3.05 \\
\hline 41.00 & 8.15 & 4.60 & 3.40 \\
\hline
\end{tabular}


Region 21 Model CRUST5.1 D9

\begin{tabular}{|c|c|c|c|}
\hline Depth & $\underline{V p}$ & $\underline{\mathrm{Vs}}$ & density \\
\hline 0.00 & 2.50 & 1.10 & 2.10 \\
\hline 0.50 & 4.00 & 2.10 & 2.40 \\
\hline 1.00 & 6.20 & 3.60 & 2.80 \\
\hline 17.00 & 6.60 & 3.70 & 2.90 \\
\hline 32.00 & 7.30 & 4.00 & 3.10 \\
\hline 41.00 & 8.20 & 4.63 & 3.40 \\
\hline
\end{tabular}

Region 22, 23 Model CRUST5.1 D6

\begin{tabular}{|c|c|c|c|}
\hline Depth & $\underline{\mathrm{Vp}}$ & $\underline{\mathrm{Vs}}$ & $\underline{\text { density }}$ \\
\hline 0.00 & $\overline{2.50}$ & $\overline{1.10}$ & 2.10 \\
\hline 0.50 & 4.00 & 2.10 & 2.40 \\
\hline 2.00 & 6.20 & 3.60 & 2.80 \\
\hline 17.00 & 6.60 & 3.70 & 2.90 \\
\hline 32.00 & 7.30 & 4.00 & 3.10 \\
\hline 41.00 & 8.20 & 4.63 & 3.40 \\
\hline
\end{tabular}

Region 24 Model CRUST5.1 DB

\begin{tabular}{cllll} 
Depth & & $\frac{\mathrm{Vp}}{\mathrm{V}}$ & $\mathrm{Vs}$ & density \\
\hline 0.00 & & 2.50 & 1.10 & 2.10 \\
0.50 & & 4.00 & 2.10 & 2.40 \\
3.00 & & 6.20 & 3.60 & 2.80 \\
18.00 & & 6.60 & 3.70 & 2.90 \\
32.00 & & 7.30 & 4.00 & 3.10 \\
41.00 & & 8.20 & 4.63 & 3.40
\end{tabular}

Region 25 Model CRUST5.1 P4\#

\begin{tabular}{|c|c|c|c|}
\hline Depth & $\underline{V p}$ & $\underline{\mathrm{Vs}}$ & density \\
\hline 0.00 & 2.50 & $\overline{1.10}$ & 2.10 \\
\hline 0.50 & 4.00 & 2.10 & 2.40 \\
\hline 1.00 & 6.10 & 3.50 & 2.75 \\
\hline 21.00 & 6.30 & 3.60 & 2.80 \\
\hline 41.00 & 7.20 & 4.00 & 3.10 \\
\hline 50.00 & 8.00 & 4.52 & 3.35 \\
\hline
\end{tabular}

Region 26 Model CRUST5.1 N4*

\begin{tabular}{|c|c|c|c|}
\hline Depth & $\underline{V p}$ & $\underline{\text { Vs }}$ & density \\
\hline 0.00 & 2.50 & 1.10 & 2.10 \\
\hline 1.00 & 5.00 & 2.90 & 2.50 \\
\hline 2.00 & 6.10 & 3.50 & 2.75 \\
\hline 13.00 & 6.30 & 3.60 & 2.80 \\
\hline 24.00 & 6.60 & 3.60 & 2.90 \\
\hline 35.00 & 8.00 & 4.52 & 3.35 \\
\hline
\end{tabular}


Region 27_Model CRUST5.1 P2*\&

\begin{tabular}{|c|c|c|c|}
\hline Depth & Vp & $\underline{\mathrm{Vs}}$ & density \\
\hline 0.00 & 2.50 & $\overline{1.10}$ & 2.10 \\
\hline 1.00 & 4.00 & 2.10 & 2.40 \\
\hline 2.00 & 6.10 & 3.50 & 2.75 \\
\hline 16.00 & 6.30 & 3.60 & 2.80 \\
\hline 31.00 & 7.20 & 4.00 & 3.10 \\
\hline 42.00 & 8.00 & 4.52 & 3.35 \\
\hline
\end{tabular}

Region 27A_Model CRUST5.1 N2\#

\begin{tabular}{|c|c|c|c|}
\hline Depth & $\underline{V p}$ & $\underline{\mathrm{Vs}}$ & density \\
\hline 0.00 & 2.50 & $\overline{1.10}$ & 2.10 \\
\hline 1.00 & 4.00 & 2.10 & 2.40 \\
\hline 2.00 & 6.10 & 3.50 & 2.75 \\
\hline 11.00 & 6.30 & 3.60 & 2.80 \\
\hline 21.00 & 6.60 & 3.60 & 2.90 \\
\hline 31.00 & 8.00 & 4.52 & 3.35 \\
\hline
\end{tabular}

Region 28 Model CRUST5.1 N2*\#

\begin{tabular}{|c|c|c|c|}
\hline Depth & $\underline{V p}$ & $\underline{\mathrm{VS}}$ & densit \\
\hline 0.00 & 2.50 & 1.10 & 2.10 \\
\hline 1.00 & 5.00 & 2.90 & 2.50 \\
\hline 2.00 & 6.10 & 3.50 & 2.75 \\
\hline 11.00 & 6.30 & 3.60 & 2.80 \\
\hline 23.00 & 6.60 & 3.60 & 2.90 \\
\hline 33.00 & 8.00 & 4.52 & 3.35 \\
\hline
\end{tabular}

Region 29 Model CRUST5.1 P1*\#

\begin{tabular}{|c|c|c|c|}
\hline Depth & $V p$ & Vs & densit \\
\hline 0.00 & 2.50 & 1.10 & 2.10 \\
\hline 2.00 & 4.00 & 2.10 & 2.40 \\
\hline 4.00 & 6.10 & 3.50 & 2.75 \\
\hline 24.00 & 6.30 & 3.60 & 2.80 \\
\hline 44.00 & 7.20 & 4.00 & 3.10 \\
\hline 48.00 & 8.00 & 4.52 & 3.35 \\
\hline
\end{tabular}




\section{MENA1.0}

$20^{\circ} \mathrm{W} 15^{\circ} \mathrm{W} 10^{\circ} \mathrm{W} 5^{\circ} \mathrm{W} \quad 0^{\circ} \quad 5^{\circ} \mathrm{E} \quad 1^{\circ} \mathrm{E} 15^{\circ} \mathrm{E} 20^{\circ} \mathrm{E} 25^{\circ} \mathrm{E} 30^{\circ} \mathrm{E} 35^{\circ} \mathrm{E} 40^{\circ} \mathrm{E} 45^{\circ} \mathrm{E} 50^{\circ} \mathrm{E} 55^{\circ} \mathrm{E} 60^{\circ} \mathrm{E} 65^{\circ} \mathrm{E} 70^{\circ} \mathrm{E} 75^{\circ} \mathrm{E}$

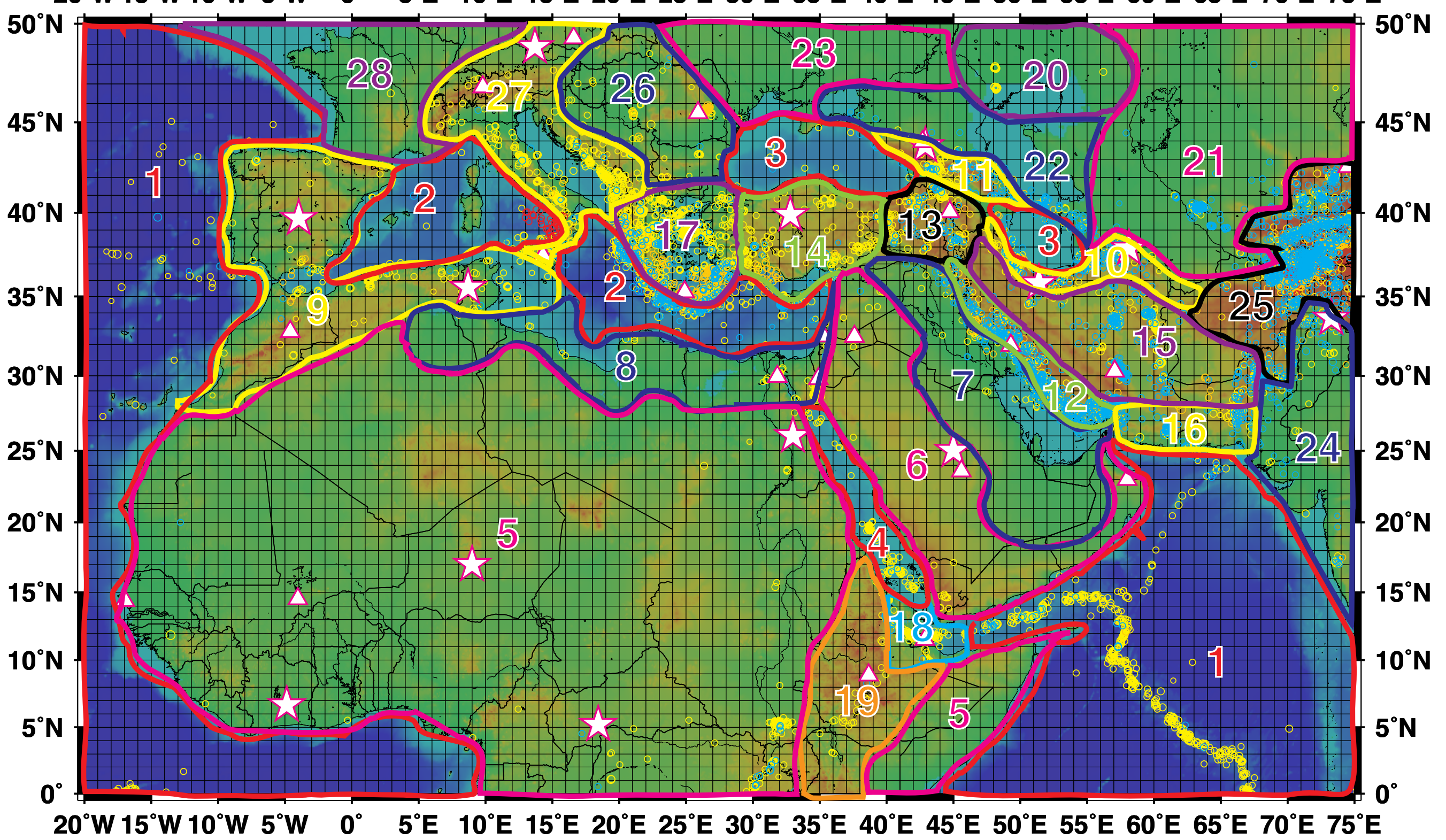

Fig. 1. 


\section{MENA 1.1}

$20^{\circ} \mathrm{W} 15^{\circ} \mathrm{W} 10^{\circ} \mathrm{W} 5^{\circ} \mathrm{W} \quad 0^{\circ} \quad 5^{\circ} \mathrm{E} \quad 1^{\circ} \mathrm{E} 15^{\circ} \mathrm{E} 20^{\circ} \mathrm{E} 25^{\circ} \mathrm{E} 30^{\circ} \mathrm{E} 35^{\circ} \mathrm{E} 40^{\circ} \mathrm{E} 45^{\circ} \mathrm{E} 50^{\circ} \mathrm{E} 55^{\circ} \mathrm{E} 60^{\circ} \mathrm{E} 65^{\circ} \mathrm{E} 70^{\circ} \mathrm{E} 75^{\circ} \mathrm{E}$

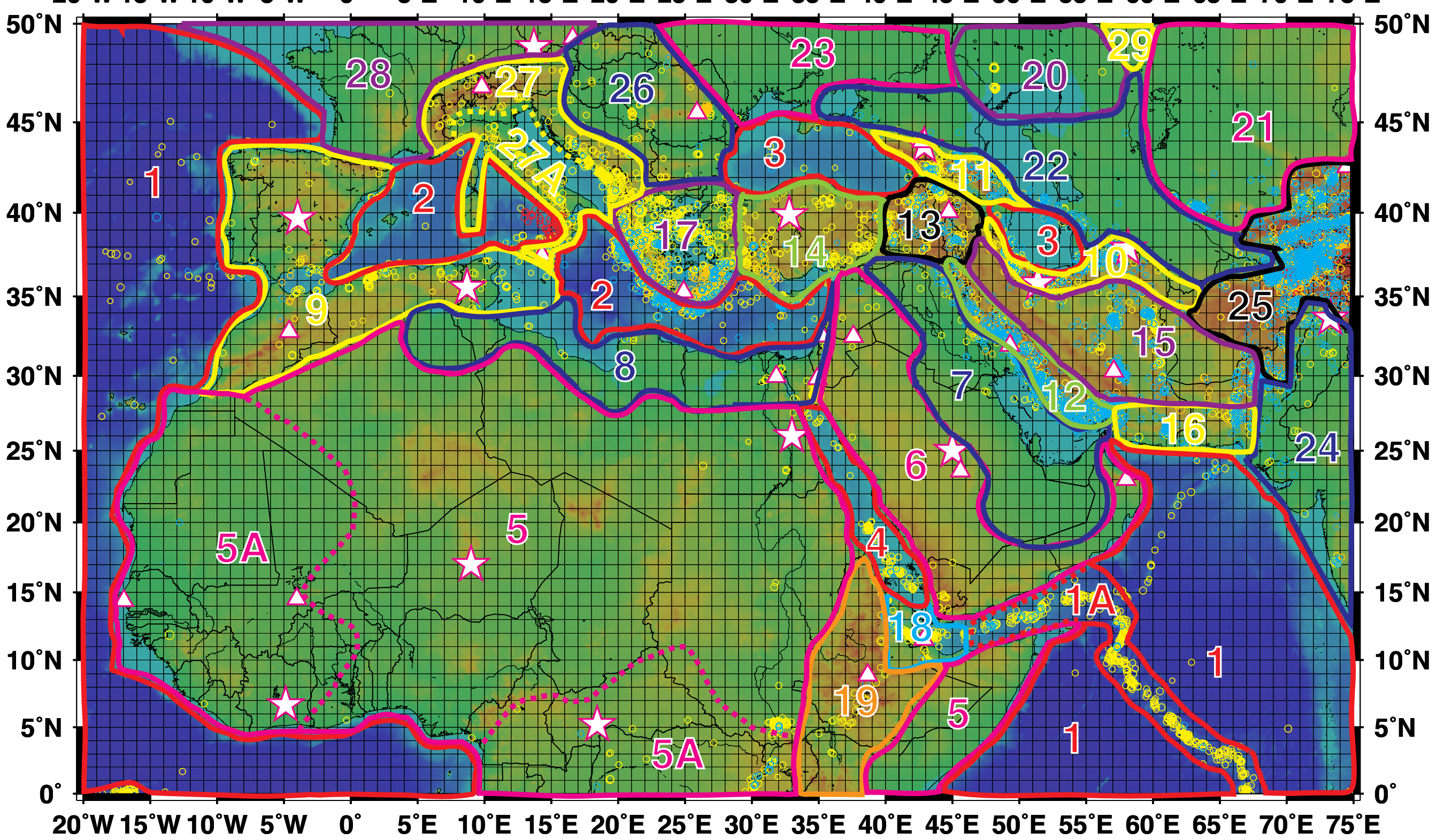

Fig 2 


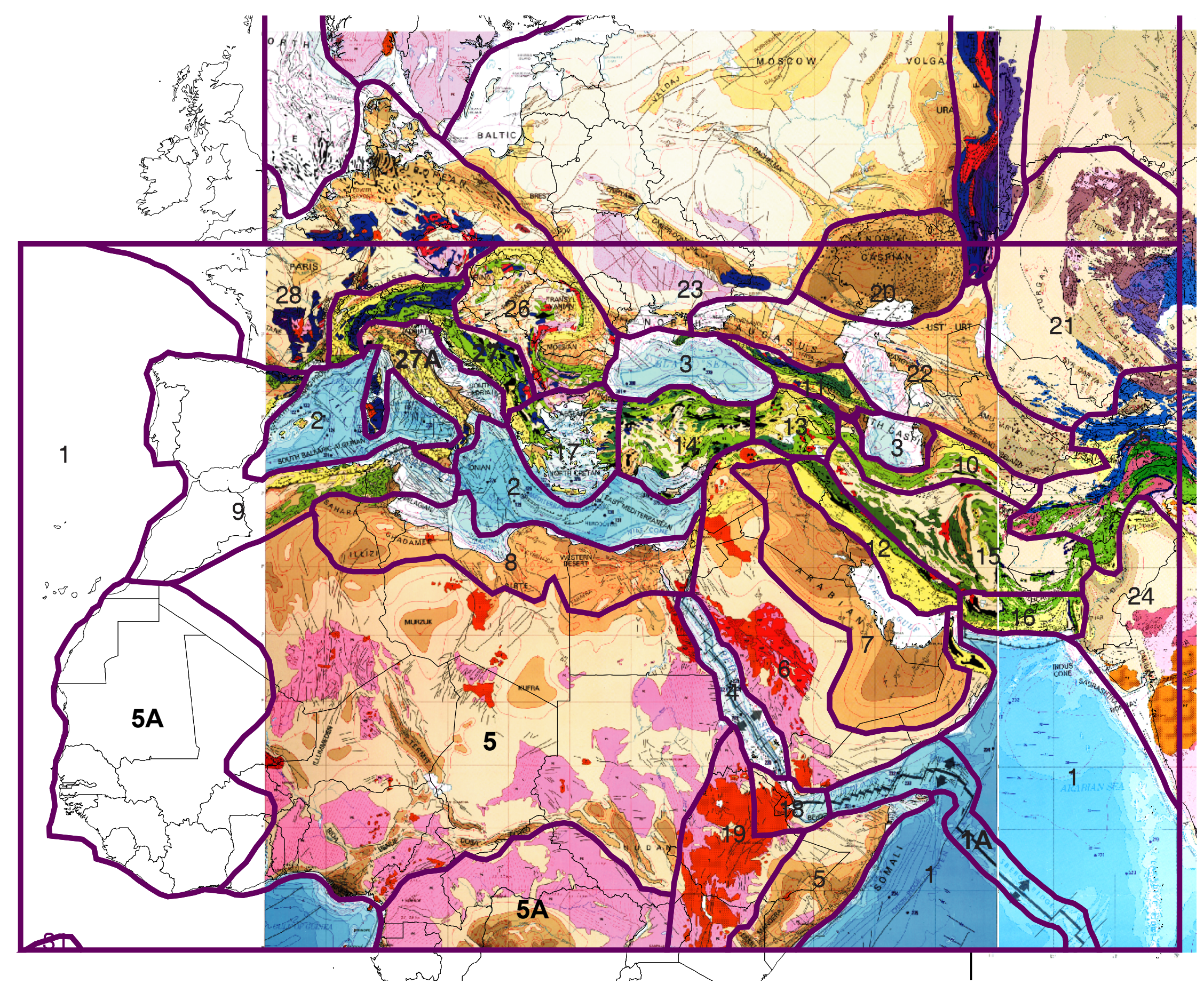

Fig. 3. 


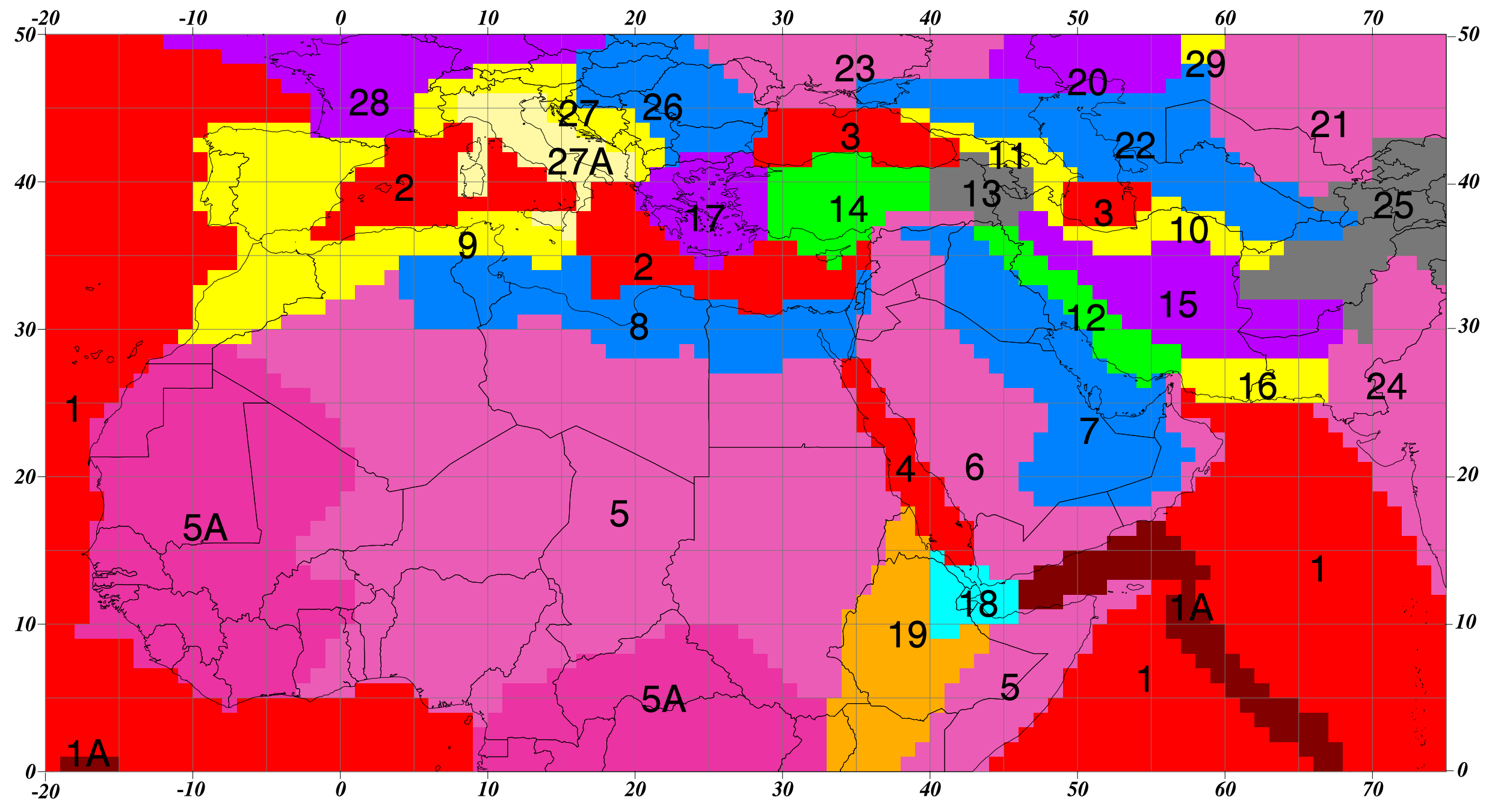

Fig. 4 